\title{
A TOP2A-derived cancer panel drives cancer progression in papillary renal cell carcinoma
}

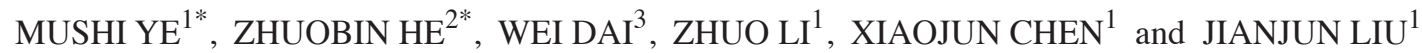 \\ ${ }^{1}$ Department of Urological Surgery, Affiliated Hospital of Guangdong Medical University, \\ Zhanjiang, Guangdong 524001; ${ }^{2}$ Department of Urological Surgery, Da Lang Hospital of Dongguan, \\ Dongguan, Guangdong 523770; ${ }^{3}$ Department of Hepatobiliary Surgery, Affiliated Hospital of \\ Guangdong Medical University, Zhanjiang, Guangdong 524001, P.R. China
}

Received May 29, 2017; Accepted February 23, 2018

DOI: $10.3892 / \mathrm{ol} .2018 .9179$

\begin{abstract}
The aim of the present study was to investigate the function of the DNA topoisomerase II $\alpha$ (TOP2A) gene and its associated genes in the progression of papillary renal cell carcinoma (PRCC). Online cancer databases, including cBioportal, Oncomine, OncoLnc and Search Tool for the Retrieval of Interacting Genes/Proteins were used to analyze the TOP $2 A$ gene expression profile, function and regulation network in PRCC. The genes that were significantly co-expressed or mutually exclusively expressed with $T O P 2 A$ were identified. The genes co-expressed with $T O P 2 A$ were defined as a 'TOP $2 A$-cancer panel', which cooperatively promotes $\mathrm{PRCC}$ progression. This gene panel performed well in predicting the prognosis of PRCC. In addition, the TOP $2 A$-cancer panel significantly affected the outcome of PRCC compared with clear cell renal cell carcinoma (CCRCC). The protein-protein interaction network of all genes associated with TOP $2 A$ was also generated. This interaction network may provide foundation for the additional investigation of $T O P 2 A$. Integrative understating of the $T O P 2 A$-cancer panel may result in a novel avenue for treatment intervention in PRCC.
\end{abstract}

\section{Introduction}

Cancer is a multi-gene-associated disease; the genes involved in each malignancy compose a 'cancer panel'. This 'cancer panel' results in a complex protein regulation

Correspondence to: Dr Jianjun Liu, Department of Urological Surgery, Affiliated Hospital of Guangdong Medical University, 57 Renmin Road, Zhanjiang, Guangdong 524001, P.R. China E-mail: jianjunliulab@163.com

*Contributed equally

Key words: papillary renal cell carcinoma, DNA topoisomerase $\mathrm{II} \alpha$, cancer panel network that is able to determine the patterns of cancer cell behavior $(1,2)$. Therefore, treatments targeting single genes may result in failure, as there are compensatory effects elicited by other genes that occur when a single pathway is blocked (3-5). Therefore, it is necessary to identify these 'cancer panels' in each type of cancer to promote an improved understanding of cell signaling transduction networks and enable the development of higher-efficacy treatments to control cancer cells.

PRCC is the second most common type of kidney cancer. It is also the most malignant type, without any effective therapies (6). Optimal treatment involves surgical removal of the tumor when the disease is in the early stages. However, there remains a lack of treatment options for patients with advanced-stage PRCC (7). Personalized medicine has aimed to distinguish the genetic differences or gene expression pattern alterations in each patient to enable physicians to provide the best treatment for the individual. Cancer is a heterogenetic disease in terms of somatic mutations or gene expression profile alterations in cancer cells (8). Differences in the patterns of gene expression determine the course of treatment to be administered. Therefore, the present study collected data from different cancer databases and integrated the data using a bioinformatics approach to identify a gene panel that affects the progress of PRCC.

DNA topoisomerase II $\alpha(T O P 2 A)$ encodes DNA topoisomerase, which is an important enzyme that releases the torsional stress when DNA undergoes DNA replication and transcription (9). TOP $2 A$ actively participates in cellular proliferation (10). It is a critical gene in carcinogenesis $(11,12)$. Additionally, mutations in TOP $2 A$ are a common cause of the failure of drugs that target the corresponding protein (11). There are numerous data demonstrating that TOP $2 A$ is involved in a range of cancer types, including breast, endometrial, colon and ovarian cancer (13-16).

The kidney epitheilal cell is a differentiated cell type. $T O P 2 A$ is absent or expressed at low levels in kidney epithelial cells (17). A previous study revealed that TOP $2 A$ was upregulated in clear cell renal cell carcinoma (CCRCC), and that its expression was predictive of a poor patient outcome (18). Therefore, the present study aimed to identify whether TOP $2 \mathrm{~A}$ was also upregulated in PRCC and its function as a cancer 
driver, and attempted to mine data online using a bioinformatics approach to examine the cancer panel associated with TOP2A in PRCC.

\section{Materials and methods}

Bioinformatics analysis. The Cancer Genome Atlas (TCGA) was joint project launched by the National Cancer Institute and National Human Genome Research Institute, has generated comprehensive, multi-dimensional maps of the key genomic changes in 33 types of human cancer (https://cancergenome. nih.gov/) (19). The present study used the kidney cancer dataset in TCGA. The Oncomine cancer database is a comprehensive cancer database including almost all types of cancer (20). The present study assessed the copy number and gene expression levels of TOP $2 A$ in Oncomine (https://www. oncomine.org/resource) by searching the gene symbol and cancer type within the 'Cancer vs. Normal Analysis' analysis type filter on 21th March 2017. Furthermore, the outlier analysis tool of Oncomine was used to identify the 'outlier genes' that are only expressed in a number of cancer samples on 21th March 2017. The outlier set in the TOP2A positive sample accounted for 5-25\% among all samples in the three independent studies (21-23). The survival rate curves were created using OncoLnc (http://www.OncoLnc.org/) on 27th March 2017 (24). The high and low expression groups were set at the upper and lower quartiles, respectively. The high TOP2A expression group was set at $>394.46$; whilst, the low TOP2A expression group was set at $<99.61$. Using OncoLnc, the survival curve, the Cox coefficient and the false discovery rate (FDR) were calculated on 27th March 2017. Multiple gene survival analysis was performed using survival tool in cBioPortal for Cancer Genomics (http://www.cbioportal.org) by searching the genes name simultaneously on 1st April $2017(25,26)$. The data for the generation of the heat map was downloaded from cBioPortal and hierarchical clustering was performed with $\mathrm{MeV}$ software version 4.9.0 developed by GitHub on 11th April 2017 (http://mev.tm4.org/\#/welcome). The protein-protein interaction network was completed using the Search Tool for the Retrieval of Interacting Genes/Proteins (STRING, version 10.5) by inputting all the genes on 16th April 2017 (http://string-db.org/).

Statistical analysis. One-way analysis of variance was conducted to analyze variance among multiple groups and a Student-Newman-Keuls test was used for post-hoc comparisons between the groups. Unpaired Student's t-test was performed for the comparison of mean values of two groups. Pearson's correlation analysis was conducted to test the correlation between genes. All these data analysis were performed using Graphpad Prism 5.0 (GraphPad Software, Inc., La Jolla, CA, USA) and the data were presented as the mean \pm the standard deviation. Kaplan Meier analysis was used to compare the survival time between two groups with different expression levels of the genes of interest by OncoLnc. The log-rank test was conducted to compare the survival time distribution of the two groups. Hierarchical clustering was conducted for the generation of the gene expression signature heat map using MeV (Version 4.9.0) developed by GitHub, Inc. (San Francisco, CA, USA). Multivariate Cox regression analysis was used for evaluation of the gene expression of the genes assessed here on the patient's risk of mortality. The Cox coefficient, P-value, FDR and gene rank were calculated using the OncoLnc multivariate Cox regressions model tool (24). $\mathrm{P}<0.05$ was considered to indicate a statistically significant difference.

\section{Results}

TOP $2 \mathrm{~A}$ is upregulated, and high expression of TOP $2 \mathrm{~A}$ contributes to poor outcome in PRCC. The Cancer Genome Atlas dataset of renal cell carcinoma, which includes 1,017 cases, was analyzed by Oncomine and it was identified that the TOP $2 A$ gene copy number in PRCC was significantly increased, compared with kidney or CCRCC (Fig. 1A; $\left.\mathrm{P}=5.3 \times 10^{-5}\right)$. Whether the increase in gene copy number contributed to the upregulation of TOP $2 A$ was then assessed. The association between the copy number and its expression level was then analyzed in 23 normal kidney tissues and 11 PRCC tissues. No difference in the expression of TOP $2 \mathrm{~A}$ was observed between the PRCC tissues and normal kidney tissues (Fig. 1B; $\mathrm{P}=0.187$ ). Owing to the heterogeneity of this cancer type, whether the TOP $2 A$ gene was upregulated only in certain patients with a specific genetic background. Therefore, the Oncomine outlier analysis tool was utilized, and 193 patient tumor tissues from 3 independent studies were analyzed (21-23). It was identified that TOP $2 A$ was expressed in a subset of patients with high expression of TOP $2 A$ (Fig. 1C); its association with the outcome of patients was additionally investigated. The difference in survival rates between the TOP $2 A$ high- and low-expression groups was analyzed using the Cox regression model, and it was identified that $T O P 2 A$ expression was negatively associated with patient outcome (Fig. 1D; $\mathrm{P}=1.67 \times 10^{-6}$ ). It was concluded that TOP $2 \mathrm{~A}$ was upregulated in one subset of patients with PRCC, and was predictive of poor prognosis.

Co-expressed/mutually exclusively-expressed genes with TOP $2 A$ and their role in PRCC. Pearson's correlation analysis was performed, and it was identified that the expression levels of a large number of genes were correlated with TOP $2 \mathrm{~A}$. Genes with correlation coefficients $>0.9$ were screened out for additional analysis. The genes co-expressed with the TOP $2 A$ were: Abnormal spindle microtubule assembly $(A S P M)$, exonuclease 1 (EXO1), TPX2, microtubule nucleation factor (TPX2), kinesin family member 14 (KIF14), cytoskeleton associated protein 2 like (CKAP2L), KIF20A, NUF, NDC80 kinetochore complex component (NUF2) and centromere protein $\mathrm{F}(C E N P F)$. The genes that were inversely expressed with $T O P 2 A$ were also probed. Pearson's correlation analysis was performed, and genes with correlation coefficients $<-0.3$ were selected. These genes included tumor protein P53 inducible nuclear protein 2 (TP53INP2), Rab interacting lysosomal protein $(R I L P)$, fucokinase $(F U K)$, inositol monophosphatase 2 (IMPA2), SPG7, paraplegin matrix AAA peptidase subunit (SPG7) and synaptogyrin 1 (SYNGRI). A heat map for visualizing the association between these genes was generated. The gene expression profiles in the patient tumor tissues were characterized, and the two gene sets of genes that were mutually exclusively-expressed in tumor tissues were identified (Fig. 2). 

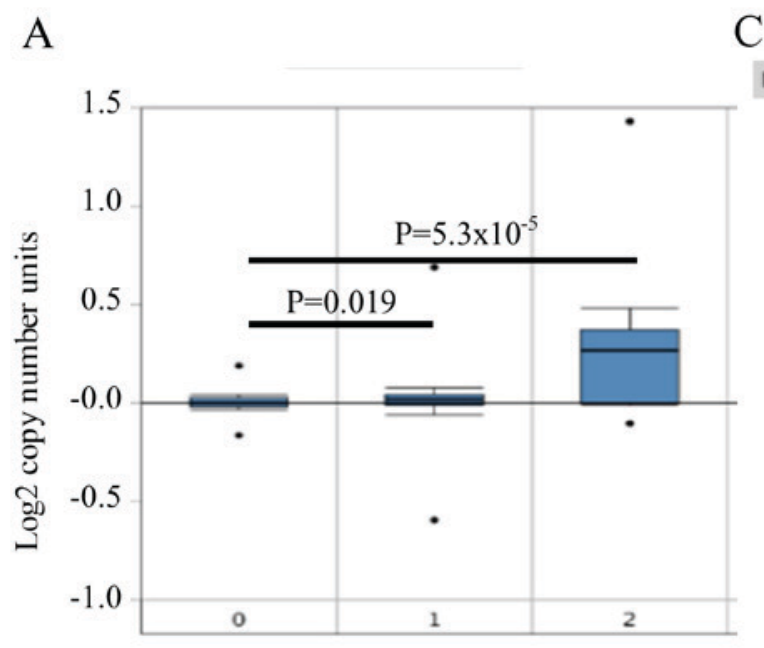

\begin{tabular}{|c|c|c|c|c|c|}
\hline Median Rank & COPA & Gene & & & \\
\hline 389.0 & 2.153 & XPNPEPZ & & & \\
\hline 393.0 & 2.147 & MECOM & & & \\
\hline 395.0 & 2.286 & F11 & & & \\
\hline 396.0 & 1.856 & $A Z 12$ & & & \\
\hline 399.0 & 1.855 & SNXS & & & \\
\hline 403.0 & 1.850 & ITGB3 & & & \\
\hline 417.0 & 2.104 & TOP ZA & & & \\
\hline 426.0 & 2.092 & DPYSL4 & & & \\
\hline 426.0 & 2.253 & OLFM1 & & & \\
\hline 428.0 & 2.091 & LCN2 & & & \\
\hline 428.0 & 2.150 & C 40 rf 33 & & & \\
\hline 429.0 & 1.830 & C7orf68 & & & \\
\hline 431.5 & 2.054 & LOC645188 & & & \\
\hline 433.0 & 2.076 & SLC $16 A 1$ & & & \\
\hline 445.0 & 1.818 & $1 \mathrm{CL} 3$ & & & \\
\hline 445.5 & 2.036 & ATE 1 & & & \\
\hline 446.0 & 1.818 & LRPSL & & & \\
\hline 450.0 & 2.052 & TREH & & & \\
\hline 455.0 & 2.045 & CYSLTRZ & & & \\
\hline \multirow[t]{2}{*}{455.0} & 2.055 & WNK3 & & & \\
\hline & & & 1 & 2 & 3 \\
\hline
\end{tabular}

B

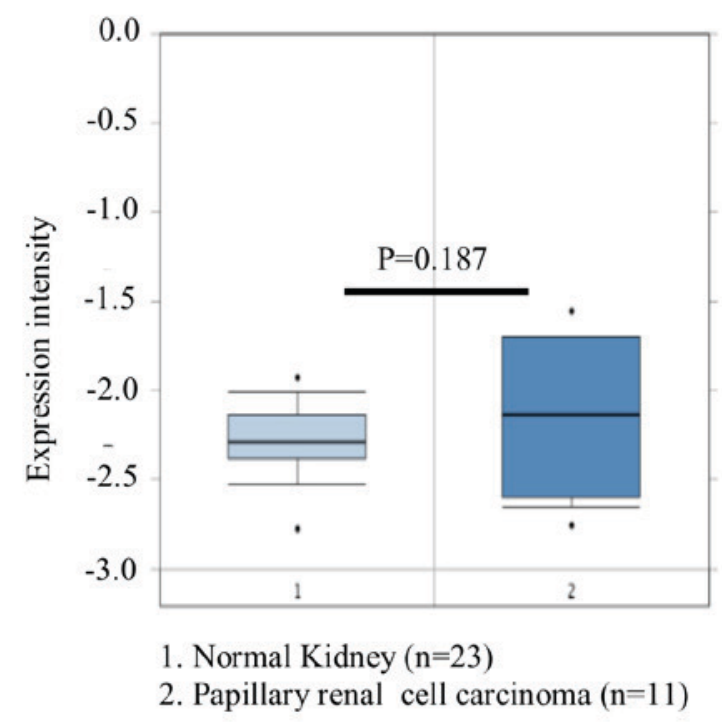

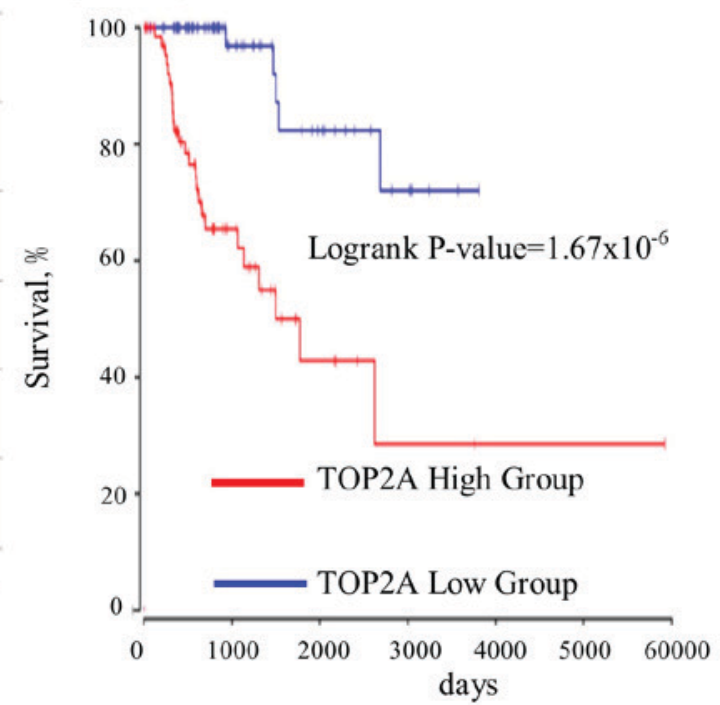

Figure 1. TOP2A is dysregulated in a subset of patients with PRCC and predicts poor outcome. (A) The copy number of TOP2A in PRCC was increased, compared with clear cell renal cell carcinoma and normal kidney tissue. (B) There was no significant differential expression of TOP $2 A$ in the tissues of PRCC and normal kidney cells. (C) TOP $2 A$ was upregulated in a subset of patients with PRCC using outlier analysis. (D) High expression of TOP2A in patients with PRCC predicts a poor survival rate. TOP2A, DNA topoisomerase II $\alpha$; COPA, copy number. PRCC, papillary renal cell carcinoma.

Furthermore, the two sets of genes were compared in CCRCC and PRCC. Not only was the expression level rank but also the Cox regression coefficient was significantly lower in the CCRCC compared with PRCC (Table I).

TOP $2 A$ cancer panel predicts prognosis in PRCC. The roles of the genes in the TOP $2 A$ 'panel' in PRCC remain elusive. A survival curve analysis for each gene between their respective high- and low-expression groups was performed. It was identified that these genes were good prognostic markers. Notably, these genes performed better in predicting prognosis of the patient in PRCC compared with CCRCC (Table I). ASPM, TPX2, CENPF, hyaluronan mediated motility receptor (HMMR), EXO1, KIF14, KIF20A, NUF2, cytoskeleton associated protein 2 like $(C K A P 2 L)$ predicted the shortest survival time of patients (Fig. 3A-I). However, the upregulation of the mutually exclusive genes (RILP, SYNGR1, IMPA2, FUK, TP53INP2, SPG7) prolonged the patient survival time (Fig. 4A-F). Furthermore, the mutually exclusive gene expression in the patients with TOP2A high expression may counteract the decreased survival time observed in the TOP $2 A$-cancer panel gene expression analysis (Fig. 5A-C). The gene interaction network of the TOP $2 A$-associated genes was analyzed with the STRING protein interaction analysis tool, and it was observed that the gene co-expressed with TOP $2 A$ form a 'cancer panel'. The downregulated genes may serve as 'tumor repressor panel' (Fig. 5D). 


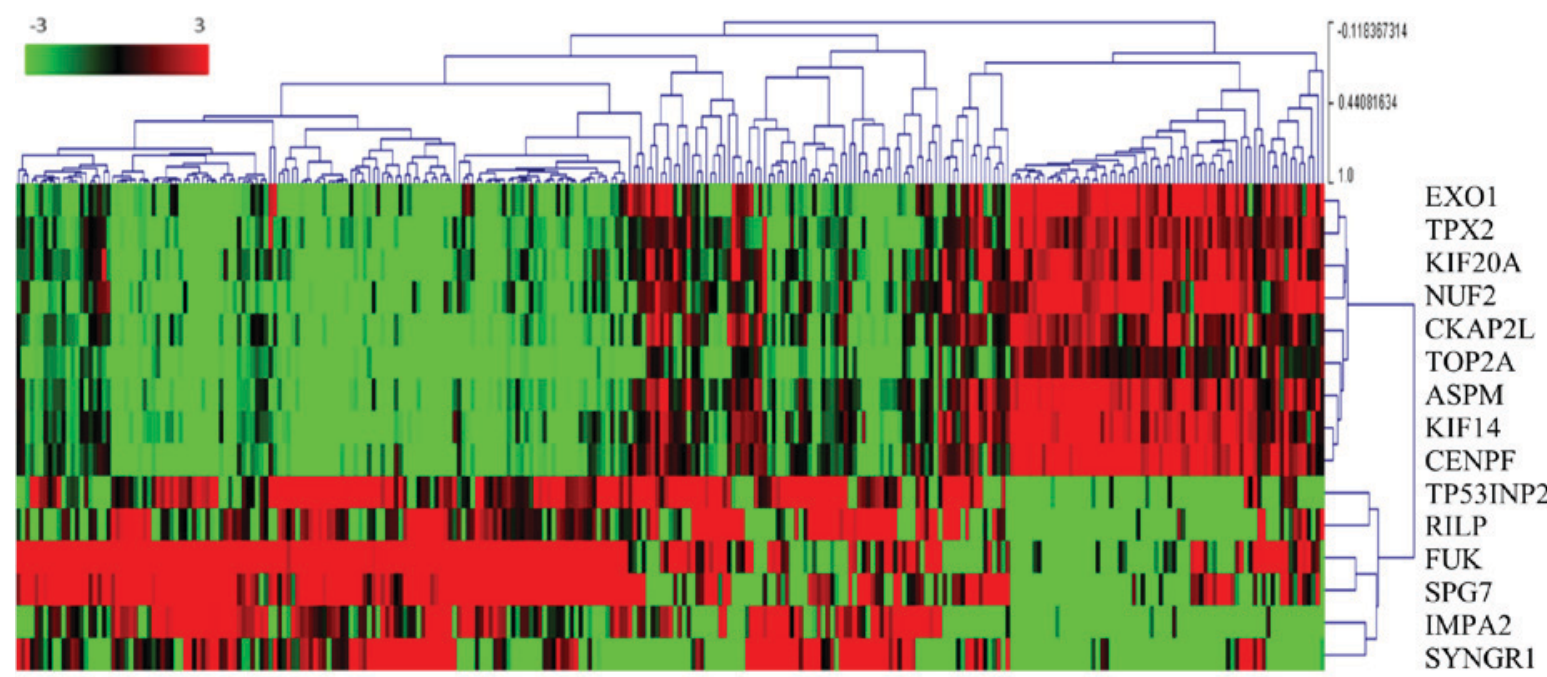

Figure 2. TOP2A co-expressed and mutually expressed genes. The heat map depicts the Log2(expression level) of TOP2A-associated genes in patients with papillary renal cell carcinoma (each column represents one case). Green to red transition represents the range from -3 to 3 of gene expression after Log2 transformation. The number next to the branches represents the gene expression correlation with other cases. The higher a correlation value is for a case, the more similar the genes expression profile in the same cluster. EXO1, exonuclease 1; TPX2, TPX2, microtubule nucleation factor; KIF20A, kinesin family member 20A; NUF2, NUF, NDC80 kinetochore complex component; CKAP2L, cytoskeleton associated protein 2 like; TOP2A, DNA topoisomerase II $\alpha$; $A S P M$, abnormal spindle microtubule assembly; KIF14, kinesin family member 14; CENPF, centromere protein F; TP53INP2, tumor protein P53 inducible nuclear protein 2; RILP, Rab interacting lysosomal protein; FUK, fucokinase; SPG7, SPG7, paraplegin matrix AAA peptidase subunit; IMPA2, inositol monophosphatase 2; SYNGR1, synaptogyrin 1.

\section{Discussion}

Oncogene mutations usually drive carcinogenesis, but gene alteration always results in the regulation of the expression of other associated genes. The expression of these associated genes may comprise a network, and their output may affect the behavior of cancer cells. These genes serve a vital role in establishing the properties of different types of cancer usually was defined as 'cancer panels' (27). The two most common types of kidney cancer are CCRCC and PRCC (28). CCRCC is sensitive to chemotherapeutics and patients generally exhibit improved outcomes following therapy compared with without therapy (29). However, PRCC often exhibits resistance to current chemotherapeutics (30). It was reported that TOP $2 A$ was upregulated in prostate cancer, breast cancer and serves as an indicator of a poor outcome $(11,31)$. Previously, a number of studies have revealed that TOP $2 A$ is upregulated in CCRCC and is a poor predicative marker for pgrognosis $(18,32)$. However, to the best of our knowledge, there are no stdies on whether TOP $2 A$ is dysregulated in PRCC. The present study identified that $T O P 2 A$ is upregulated in kidney cancer and is significantly increased in PRCC compared with CCRCC. Additionally, TOP2A functioned well in predicting the prognoses of patients with PRCC compared with in CCRCC. This result indicated that TOP $2 A$ may be involved in PRCC.

The 'cancer panel' established in the present study included genes that were involved in similar biological functions and contributed to cancer progression. These genes function concomitantly to affect the behavior of cancer cells. Identification of the associations between these genes and their interaction network may enable an improved understanding of how TOP $2 A$ causes the development of
PRCC. To intervene in cancer progression, the interruption of one driver gene is not sufficient for the complete inhibition of cancer progression. Integral disruption of all of the genes involved in cancer progression is more important for the successful treatment of cancer, than focusing on a single target gene. Therefore, the present study analyzed the genes that were closely associated with TOP $2 A$. Genes that were significantly co-expressed with $T O P 2 A$ were selected, and it was hypothesized that these genes may be simultaneously involved in PRCC progression. To confirm the function of these genes in PRCC, the survival curves for the high- and low-expression groups of each gene were generated. Notably, it was identified that the expression of these genes significantly reduced the survival time of patients. Therefore, the expression levels of these genes was not only associated with TOP $2 A$, but also upregulation of these genes would reduce the survival rates of the patients. This result indicated that $T O P 2 A$ may prompt PRCC progression in conjunction with other genes; however, whether TOP $2 \mathrm{~A}$ regulates the expression of these genes requires additional investigation.

Considering the genes in the 'TOP2A-cancer panel', the present study aimed to identify the processes they are involved in, and to understand how these genes function together to determine cancer cell properties. The ASPM gene is closely associated with spindle function, which is involved in cell mitosis (33). The TPX2 gene is a spindle assembly factor that servers as a critical role in $\mathrm{G}_{2} / \mathrm{M}$ transition of cell cycle (34). The HMMR gene encodes a protein that forms a complex with $B R C A 1 / 2$, which promotes cell proliferation and increases the risk of cancer (35). The CENPF gene is required for chromosome segregation in cell mitosis, which regulates DNA replication and cell cycle progression (36). EXO1 encodes an exonuclease that is responsible 
Table I. Comparisons of Cox coefficient, P-value, FDR and gene rank between the papillary renal cell carcinoma and clear renal cell carcinoma samples using a Cox regression model.

\begin{tabular}{|c|c|c|c|c|}
\hline \multicolumn{5}{|c|}{ A, Co-expressed genes } \\
\hline Gene/cancer types & Cox coefficient & P-value & Corrected FDR & Rank \\
\hline \multicolumn{5}{|l|}{ TOP $2 A$} \\
\hline PRCC & 1.238 & $5.10 \times 10^{-11}$ & $2.14 \times 10^{-7}$ & 3 \\
\hline CCRCC & 0.259 & $3.00 \times 10^{-3}$ & $1.22 \times 10^{-2}$ & 4,086 \\
\hline \multicolumn{5}{|l|}{$T P X 2$} \\
\hline PRCC & 1.23 & $4.20 \times 10^{-10}$ & $3.21 \times 10^{-7}$ & 21 \\
\hline CCRCC & 0.34 & $2.20 \times 10^{-4}$ & $1.57 \times 10^{-3}$ & 2,332 \\
\hline \multicolumn{5}{|l|}{ EXO1 } \\
\hline PRCC & 1.039 & $2.90 \times 10^{-9}$ & $9.93 \times 10^{-7}$ & 48 \\
\hline CCRCC & 0.16 & $6.00 \times 10^{-2}$ & $1.27 \times 10^{-1}$ & 7,875 \\
\hline \multicolumn{5}{|l|}{ KIF 14} \\
\hline PRCC & 1.069 & $1.80 \times 10^{-9}$ & $7.05 \times 10^{-7}$ & 42 \\
\hline CCRCC & 0.317 & $2.50 \times 10^{-4}$ & $1.74 \times 10^{-3}$ & 2,392 \\
\hline \multicolumn{5}{|l|}{$K I F 20 A$} \\
\hline PRCC & 1.266 & $9.60 \times 10^{-11}$ & $2.25 \times 10^{-7}$ & 7 \\
\hline CCRCC & 0.377 & $3.00 \times 10^{-5}$ & $3.39 \times 10^{-4}$ & 1,471 \\
\hline \multicolumn{5}{|l|}{$A S P M$} \\
\hline PRCC & 1.259 & $1.10 \times 10^{-10}$ & $2.26 \times 10^{-7}$ & 8 \\
\hline CCRCC & 0.286 & $7.60 \times 10^{-4}$ & $4.16 \times 10^{-3}$ & 3,044 \\
\hline \multicolumn{5}{|l|}{$C K A P 2 L$} \\
\hline PRCC & 1.026 & $1.10 \times 10^{-8}$ & $2.41 \times 10^{-6}$ & 73 \\
\hline CCRCC & 0.173 & $4.00 \times 10^{-2}$ & $9.22 \times 10^{-2}$ & 7,212 \\
\hline \multicolumn{5}{|l|}{$N U F 2$} \\
\hline PRCC & 1.09 & $5.70 \times 10^{-10}$ & $3.46 \times 10^{-7}$ & 27 \\
\hline CCRCC & 0.393 & $6.40 \times 10^{-6}$ & $1.03 \times 10^{-4}$ & 1,033 \\
\hline \multicolumn{5}{|l|}{$C E N P F$} \\
\hline PRCC & 1.137 & $3.00 \times 10^{-10}$ & $3.21 \times 10^{-7}$ & 15 \\
\hline CCRCC & 0.289 & $1.10 \times 10^{-3}$ & $5.50 \times 10^{-3}$ & 3,283 \\
\hline \multicolumn{5}{|c|}{ B, Mutually exclusive genes } \\
\hline \multicolumn{5}{|l|}{ TP53INP2 } \\
\hline PRCC & -0.77 & $2.00 \times 10^{-6}$ & $1.30 \times 10^{-4}$ & 253 \\
\hline CCRCC & -0.262 & $1.70 \times 10^{-3}$ & $7.78 \times 10^{-3}$ & 3,644 \\
\hline \multicolumn{5}{|l|}{$R I L P$} \\
\hline PRCC & -0.657 & $1.40 \times 10^{-4}$ & $2.59 \times 10^{-3}$ & 885 \\
\hline CCRCC & 0.099 & $2.20 \times 10^{-1}$ & $3.40 \times 10^{-1}$ & 10,750 \\
\hline \multicolumn{5}{|l|}{$F U K$} \\
\hline PRCC & -0.688 & $1.40 \times 10^{-5}$ & $4.86 \times 10^{-4}$ & 467 \\
\hline CCRCC & 0.035 & $6.40 \times 10^{-1}$ & $7.43 \times 10^{-1}$ & 14,316 \\
\hline \multicolumn{5}{|l|}{ IMPA2 } \\
\hline PRCC & -0.678 & $8.40 \times 10^{-6}$ & $3.41 \times 10^{-4}$ & 403 \\
\hline CCRCC & -0.319 & $1.70 \times 10^{-4}$ & $1.29 \times 10^{-3}$ & 2,167 \\
\hline \multicolumn{5}{|l|}{$S P G 7$} \\
\hline PRCC & -0.917 & $4.60 \times 10^{-7}$ & $4.56 \times 10^{-5}$ & 165 \\
\hline CCRCC & 0.364 & $1.80 \times 10^{-6}$ & $3.98 \times 10^{-5}$ & 751 \\
\hline \multicolumn{5}{|l|}{ SYNGRI } \\
\hline PRCC & -0.506 & $1.60 \times 10^{-3}$ & $1.39 \times 10^{-2}$ & 1,891 \\
\hline CCRCC & 0.054 & $5.20 \times 10^{-1}$ & $6.42 \times 10^{-1}$ & 13,508 \\
\hline $\begin{array}{l}\text { FDR, false discovery } \\
E X O 1, \text { exonuclease } 1 \\
\text { kinesin family memb } \\
\text { nuclear protein } 2 ; R I \\
\text { peptidase subunit; } S Y\end{array}$ & $\begin{array}{l}\text { ary renal cell carc } \\
\text { otubule nucleation } \\
\text { F, NDC80 kinetoc } \\
\text { lysosomal protei } \\
1 .\end{array}$ & $\begin{array}{l}\text { lear cell renal } \\
\text { sin family me } \\
\text { onent; CENP } \\
\text { e; IMPA2, inc }\end{array}$ & $\begin{array}{l}P M, \text { abnormal spi } \\
\text { cytoskeleton associ } \\
\text { ein F; TP53INP2, } \\
\text { tase 2; } S P G 7, \mathrm{SPC}\end{array}$ & $\begin{array}{l}\text { issembly; } \\
\text { KIF2OA, } \\
\text { inducible } \\
\text { rix AAA }\end{array}$ \\
\hline
\end{tabular}


A
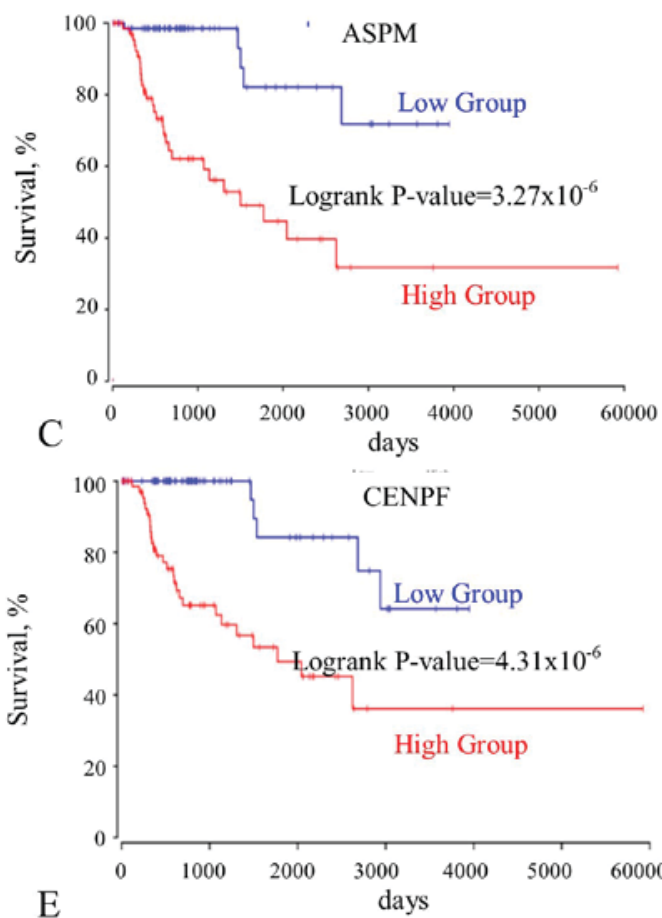

$\mathrm{E}$
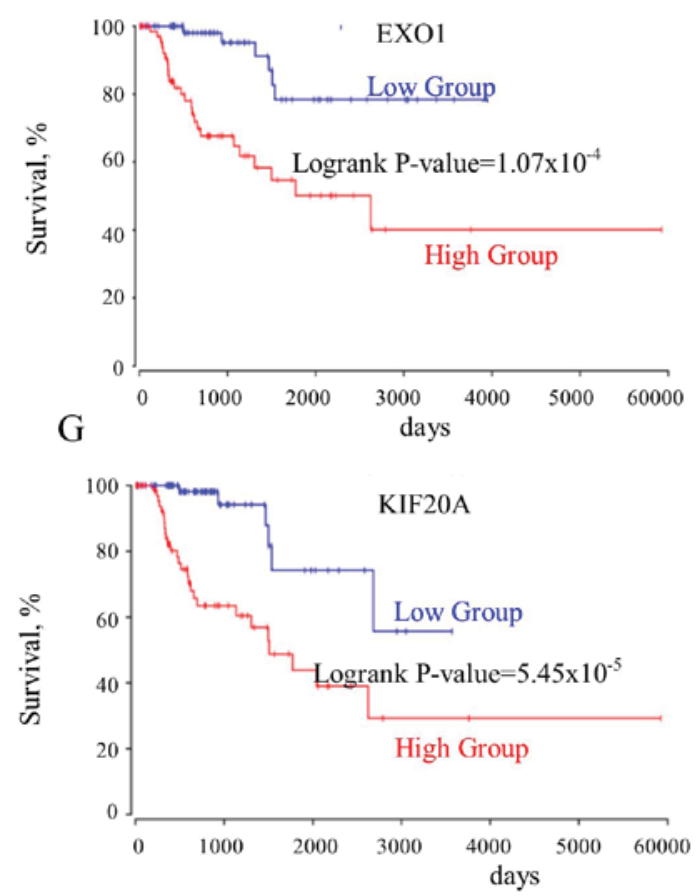

$\mathrm{B}$
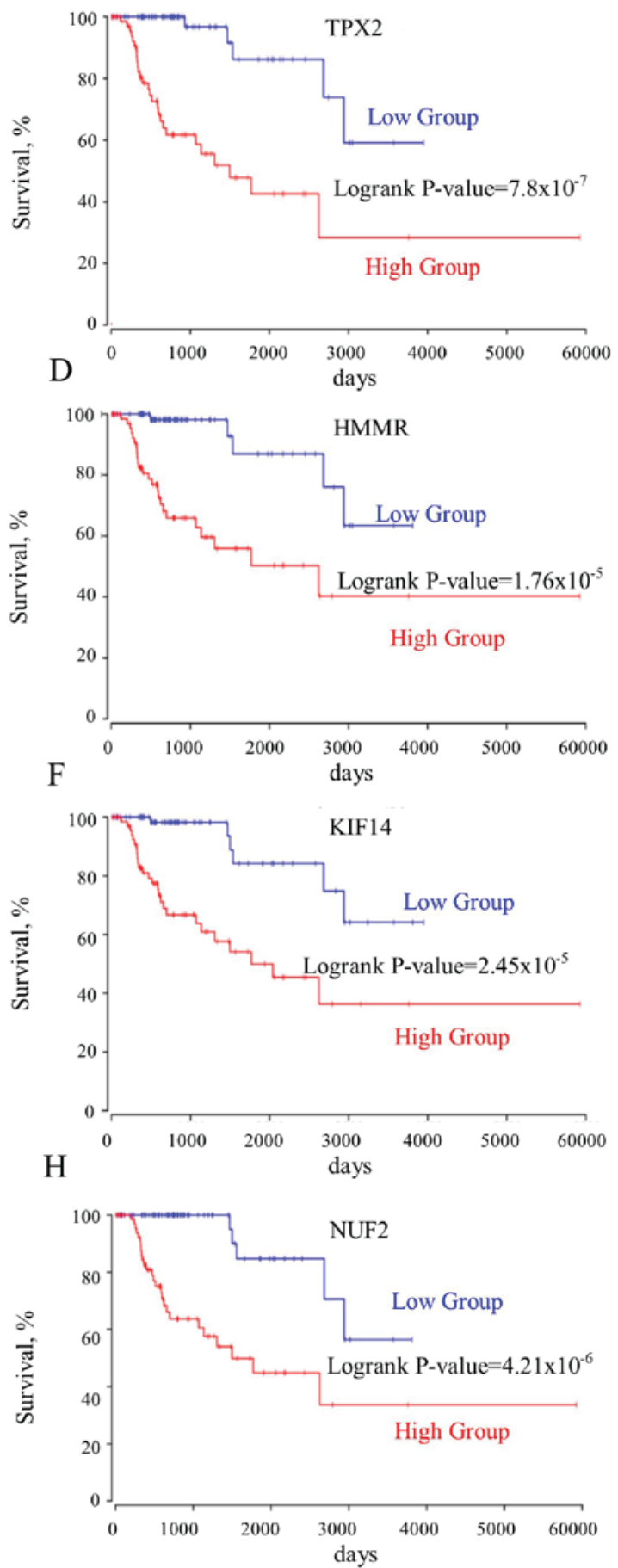

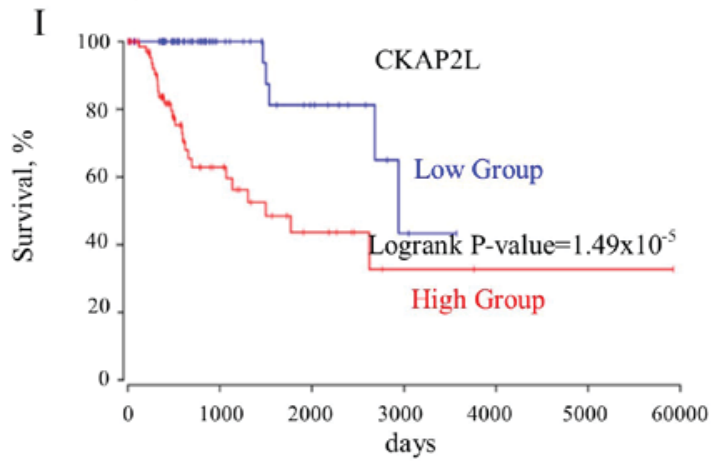

Figure 3. (A-I) All genes co-expressed with TOP $2 A$ are negatively associated with the survival rates of patients. ASPM, abnormal spindle microtubule assembly; TPX2, TPX2, microtubule nucleation factor; $C E N P F$, centromere protein F; $H M M R$, hyaluronan mediated motility receptor; $E X O 1$, exonuclease 1 ; $K I F 14$, kinesin family member 14 ; KIF20A, kinesin family member 20A; NUF2, NUF, NDC80 kinetochore complex component; $C K A P 2 L$, cytoskeleton associated protein 2 like; TOP2A, DNA topoisomerase II $\alpha$. 


\section{A}

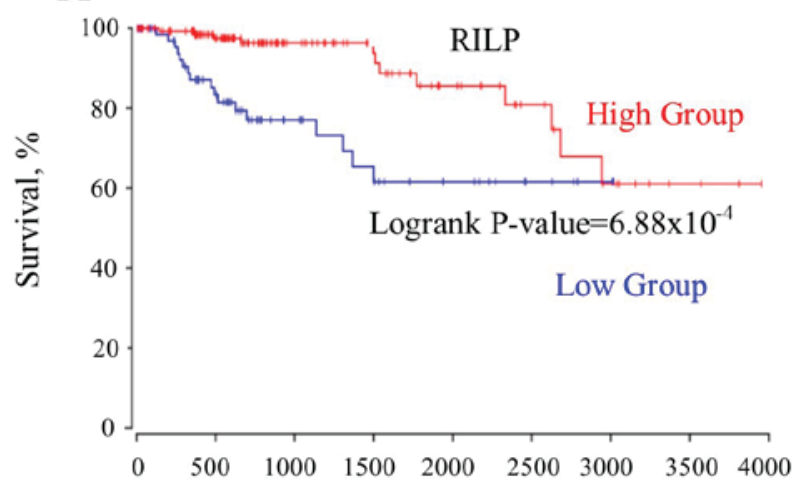

$\mathrm{C}$
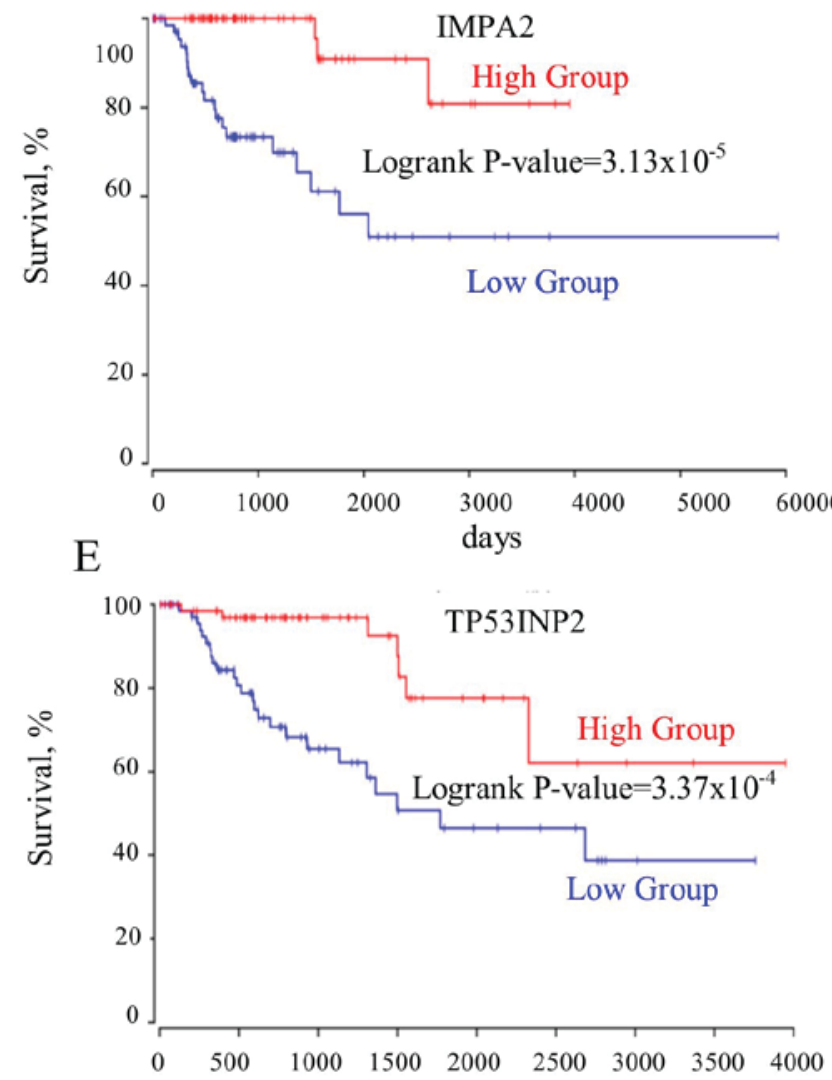

B
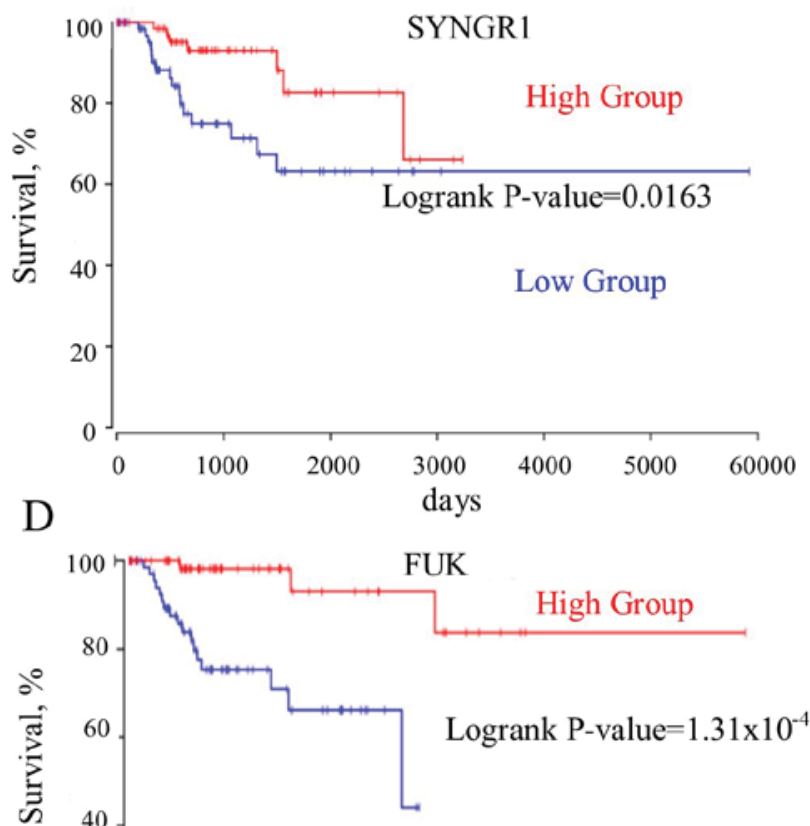

Low Group

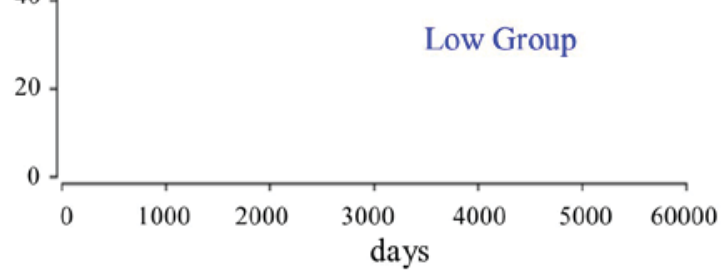

$\mathrm{F}$

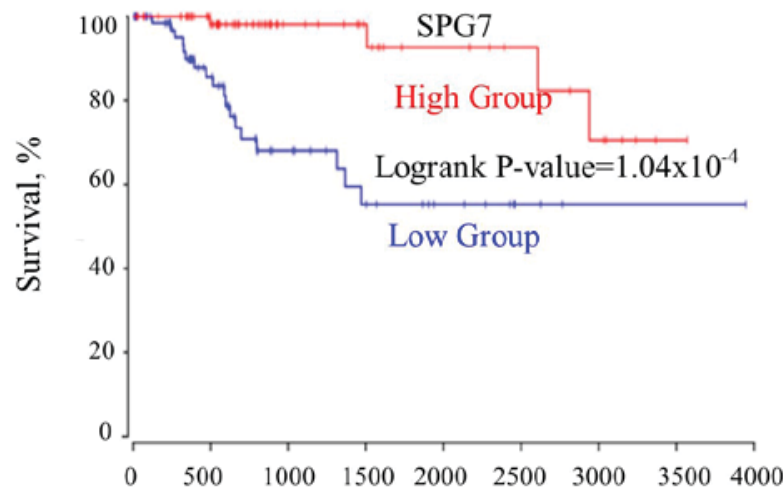

Figure 4. (A-F) All mutually exclusively expressed gene with TOP2A are positively associated with the survival rates of patients. RILP, Rab Interacting lysosomal protein; SYNGR1, synaptogyrin 1; IMPA2, Inositol monophosphatase 2; FUK, fucokinase; TP53INP2, tumor protein P53 inducible nuclear protein 2; $S P G 7$, SPG7, paraplegin matrix AAA peptidase subunit; TOP2A, DNA topoisomerase II $\alpha$.

for DNA mismatch repair (37). KIFl4 contributes to chromosome segregation and spindle formation in the mitosis process (38). KIF20A functions as a spindle assembly mediator, resulting in cell division (39). CKAP2L is involved in spindle organization (40). NUF2 regulates chromosome segregation and centromere function in the cell mitosis (41). Therefore, the genes within the TOP $2 A$-derived cancer panel function in the regulation of cell mitosis. According to the protein-protein network (Fig. 5D), the results of the present study indicated that $T O P 2 A$ may serve a vital role in the regulation of cell proliferation through interaction with the TOP2A cancer panel.

The present study compared the association between the expression levels of these genes with the survival rates of patients with CCRCC and PRCC. It was identified that these genes that coexpressed with $T O P 2 A$ significantly increase the survival rate of patients with PRCC compared with patients with CCRCC. However, the genes that inversely expressed with TOP2A decrease the survival rates of patients with PRCC compared with patients with CCRCC, which may provide a method for distinguishing between renal cell carcinoma subtypes by the expression of the TOP $2 A$ cancer panel genes. The present study identified that TOP $2 A$ was a vital prognostic marker for PRCC, and the genes involved in the network of TOP $2 A$ were examined. This network of TOP $2 A$ genes may assist in understanding how TOP $2 A$ affects cancer cells, and how targeting these genes may provide an avenue for the treatment of PRCC. 
A

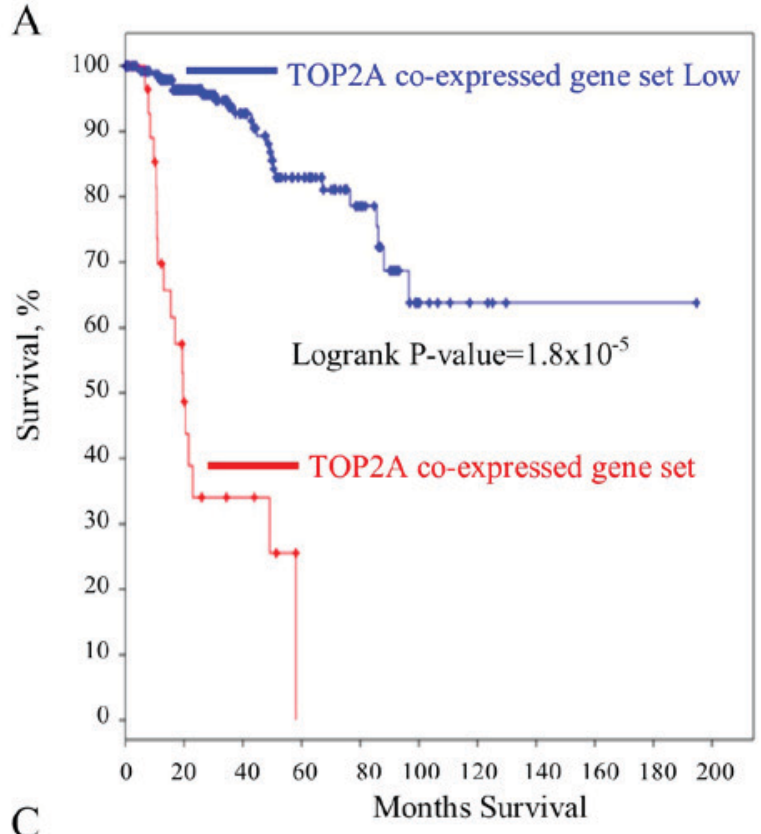

$\mathrm{C}$

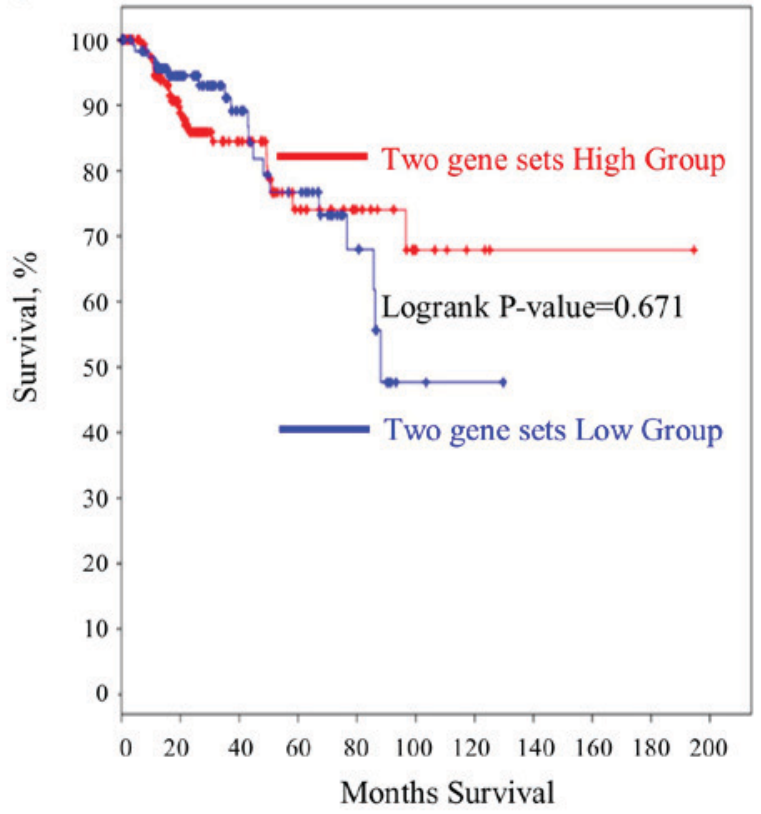

B

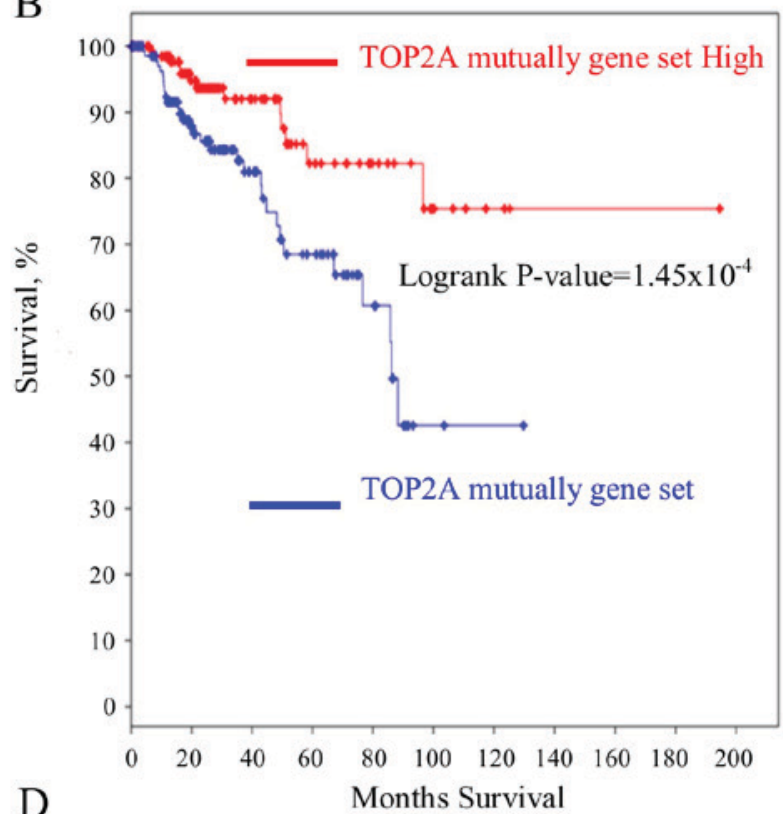

D

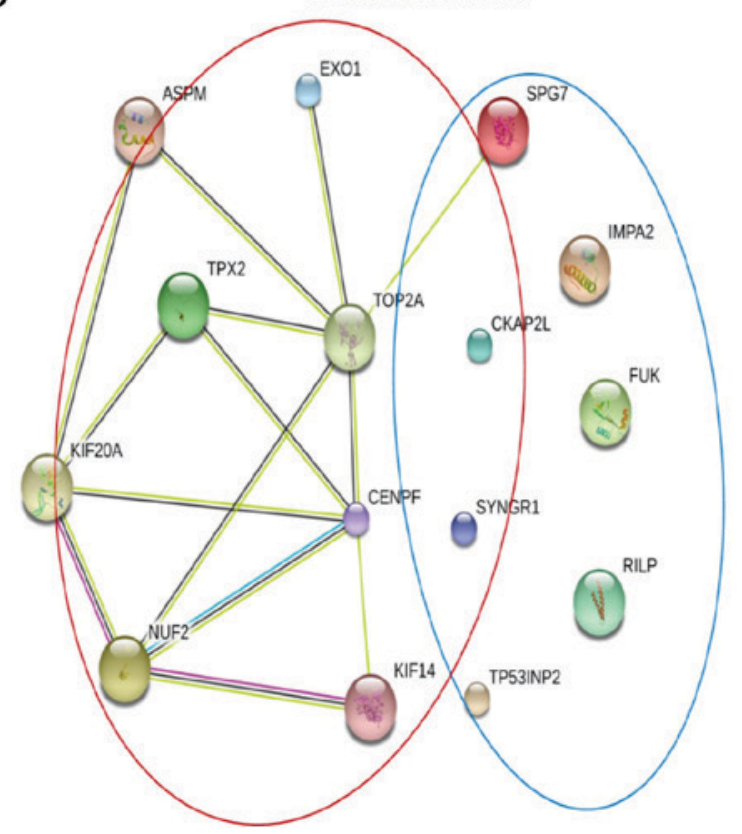

Figure 5. TOP $2 A$ mutually exclusively expressed genes counteract the TOP $2 A$ co-expressed genes on reducing the survival rates of patients and the protein-protein interaction network between all genes of TOP $2 A$-cancer gene set. (A) The survival rate of the patients with all TOP $2 A$ co-expressed gene upregulated. (B) The survival rates of the patients with all TOP $2 A$ mutually exclusively expressed gene upregulated. (C) The survival rates of patients with all the TOP2A-associated genes upregulated. (D) The protein-protein interaction network of all genes. Genes co-expressed with TOP2A are included in the red circle. Genes mutually exclusively expressed with TOP2A are included in the blue circle. TOP2A, DNA topoisomerase II $\alpha$.

\section{Acknowledgements}

The results shown here are in whole or part based upon data generated by the TCGA Research Network. The authors also would like to thank Dr. Qingyu Zhang (Faculty of Health Sciences, University of Macau, Macau, China) for providing advice on the data interpretation and critical comments on the discussion.

\section{Funding}

This present study was by partially supported by the Zhanjiang scientific research project (grant no. 2016C01005) and Zhanjiang scientific special competition project (grant no. 2016A01011).

\section{Availability of data and materials}

The datasets used and/or analyzed during the current study are available from the corresponding author on reasonable request.

\section{Authors' contributions}

MY and ZH collected data and developed the methodology. DW, ZI and XC interpreted the results. MY and JL designed the work and wrote the manuscript. 


\section{Ethics approval and consent to publish}

This study reinterpreted the data deposited in TCGA and GEO without releasing the information of patients. According to TCGA publication guidelines, there are no restrictions on the use of TCGA data for research purposes.

\section{Consent for publication}

Not applicable.

\section{Competing interests}

The authors declare that they have no competing interests.

\section{References}

1. Dalton E and Thompson J: AB054. Overview of multi-gene panels for hereditary cancer. Ann Transl Med 3: AB054, 2015.

2. Lincoln SE, Kobayashi Y, Anderson MJ, Yang S, Desmond AJ, Mills MA, Nilsen GB, Jacobs KB, Monzon FA, Kurian AW, et al: A systematic comparison of traditional and multigene pane testing for hereditary breast and ovarian cancer genes in more than 1000 patients. J Mol Diagn 17: 533-544, 2015.

3. Housman G, Byler S, Heerboth S, Lapinska K, Longacre M, Snyder N and Sarkar S: Drug resistance in cancer: An overview. Cancers (Basel) 6: 1769-1792, 2014.

4. Guo XE, Ngo B, Modrek AS and Lee WH: Targeting tumor suppressor networks for cancer therapeutics. Curr Drug Targets 15: 2-16, 2014.

5. Zhang Q, Madden NE, Wong AST, Chow BKC and Lee LTO: The role of endocrine $G$ protein-coupled receptors in ovarian cancer progression. Front Endocrinol (Lausanne) 8: 66, 2017.

6. Shuch B, Hahn AW and Agarwal N: Current treatment landscape of advanced papillary renal cancer. J Clin Oncol 35: 2981-2983, 2017.

7. Ross H, Martignoni G and Argani P: Renal cell carcinoma with clear cell and papillary features. Arch Pathol Lab Med 136: 391-399, 2012.

8. Friedman AA, Letai A, Fisher DE and Flaherty KT: Precision medicine for cancer with next-generation functional diagnostics. Nat Rev Cancer 15: 747-756, 2015.

9. Lodish H, Berk A, Zipursky SL, Matsudaira P, Baltimore D and Darnell J: The Role of topoisomerases in DNA replication. In: Molecular Cell Biology. 4th edition. W.H. Freeman, New York, NY, 2000.

10. Chen T, Sun Y, Ji P, Kopetz S and Zhang W: Topoisomerase II $\alpha$ in chromosome instability and personalized cancer therapy. Oncogene 34: 4019-4031, 2015.

11. de Resende MF, Vieira S, Chinen LT, Chiappelli F, da Fonseca FP, Guimarães GC, Soares FA, Neves I, Pagotty S Pellionisz PA, et al: Prognostication of prostate cancer based on TOP2A protein and gene assessment: TOP2A in prostate cancer. J Transl Med 11: 36, 2013.

12. Fountzilas G, Valavanis C, Kotoula V, Eleftheraki AG, Kalogeras KT, Tzaida O, Batistatou A, Kronenwett R, Wirtz RM, Bobos M, et al: HER2 and TOP2A in high-risk early breast cancer patients treated with adjuvant epirubicin-based dose-dense sequential chemotherapy. J Transl Med 10: 10, 2012.

13. Ito F, Furukawa $\mathrm{N}$ and Nakai T: Evaluation of top2a as a predictive marker for endometrial cancer with taxane-containing adjuvant chemotherapy. Int J Gynecol Cancer 26: 325-330, 2016.

14. Erriquez J, Becco P, Olivero M, Ponzone R, Maggiorotto F, Ferrero A, Scalzo MS, Canuto EM, Sapino A, Verdun di Cantogno L, et al: TOP2A gene copy gain predicts response of epithelial ovarian cancers to pegylated liposomal doxorubicin: TOP2A as marker of response to PLD in ovarian cancer. Gynecol Oncol 138: 627-633, 2015.

15. Tarpgaard LS, Qvortrup C, Nygård SB, Nielsen SL, Andersen DR, Jensen NF, Stenvang J, Detlefsen S, Brünner N and Pfeiffer P: A phase II study of epirubicin in oxaliplatin-resistant patients with metastatic colorectal cancer and TOP2A gene amplification. BMC Cancer 16: 91, 2016.
16. Wang J, Xu B, Yuan P, Zhang P, Li Q, Ma F and Fan Y: TOP2A amplification in breast cancer is a predictive marker of anthracycline-based neoadjuvant chemotherapy efficacy. Breast Cancer Res Treat 135: 531-537, 2012.

17. Cheburkin IuV, Kniazeva TG, Peter S, Kniazev IuP, Karelin MI, Shkol'nik MI, Evtushenko VI, Hanson KP, Ullrich A and Kniazev PG: Molecular portrait of human kidney carcinomas: The gene expression profiling of protein-tyrosine kinases and tyrosine phosphatases which controlled regulatory signals in the cells. Mol Biol (Mosk) 36: 480-490, 2002 (In Russian).

18. Chen D, Maruschke M, Hakenberg O, Zimmermann W, Stief CG and Buchner A: TOP2A, HELLS, ATAD2 and TET3 are novel prognostic markers in renal cell carcinoma. Urology 102: 265 e1-265 e7, 2017.

19. Grossman RL, Heath AP, Ferretti V, Varmus HE, Lowy DR, Kibbe WA and Staudt LM: Toward a shared vision for cancer genomic data. N Engl J Med 375: 1109-1112, 2016.

20. Rhodes DR, Yu J, Shanker K, Deshpande N, Varambally R, Ghosh D, Barrette T, Pandey A and Chinnaiyan AM: ONCOMINE: A cancer microarray database and integrated data-mining platform. Neoplasia 6: 1-6, 2004.

21. Jones J, Otu H, Spentzos D, Kolia S, Inan M, Beecken WD, Fellbaum C, Gu X, Joseph M, Pantuck AJ, et al: Gene signatures of progression and metastasis in renal cell cancer. Clin Cancer Res 11: 5730-5739, 2005.

22. Lenburg ME, Liou LS, Gerry NP, Frampton GM, Cohen HT and Christman MF: Previously unidentified changes in renal cell carcinoma gene expression identified by parametric analysis of microarray data. BMC Cancer 3: 31, 2003.

23. Dannull J, Su Z, Rizzieri D, Yang BK, Coleman D, Yancey D, Zhang A, Dahm P, Chao N, Gilboa E and Vieweg J: Enhancement of vaccine-mediated antitumor immunity in cancer patients after depletion of regulatory T cells. J Clin Invest 115: 3623-3633, 2005.

24. Anaya J: OncoLnc: Linking TCGA survival data to mRNAs, miRNAs, and lncRNAs. PeerJ Computer Science 2: e67, 2016.

25. Gao J, Aksoy BA, Dogrusoz U, Dresdner G, Gross B, Sumer SO, Sun Y, Jacobsen A, Sinha R and Larsson E, et al: Integrative analysis of complex cancer genomics and clinical profiles using the cBioPortal. Sci Signal 6: pl1, 2013.

26. Cerami E, Gao J, Dogrusoz U, Gross BE, Sumer SO, Aksoy BA, Jacobsen A, Byrne CJ, Heuer ML, Larsson E, et al: The cbio cancer genomics portal: An open platform for exploring multidimensional cancer genomics data. Cancer Discov 2: 401-404, 2012.

27. LaDuca H, Stuenkel AJ, Dolinsky JS, Keiles S, Tandy S, Pesaran T, Chen E, Gau CL, Palmaer E, Shoaepour K, et al: Utilization of multigene panels in hereditary cancer predisposition testing: Analysis of more than 2,000 patients. Genet Med 16: 830-837, 2014.

28. Capitanio U and Montorsi F: Renal cancer. Lancet 387: 894-906, 2016.

29. Escudier B, Eisen T, Stadler WM, Szczylik C, Oudard S, Siebels M, Negrier S, Chevreau C, Solska E, Desai AA, et al: Sorafenib in advanced clear-cell renal-cell carcinoma. N Engl J Med 356: 125-134, 2007.

30. Ronnen EA, Kondagunta GV, Ishill N, Spodek L, Russo P, Reuter V, Bacik J and Motzer RJ: Treatment outcome for metastatic papillary renal cell carcinoma patients. Cancer 107: 2617-2621, 2006.

31. Wang J, Xu B, Yuan P, Zhang P, Li Q, Ma F and Fan Y: TOP2A amplification in breast cancer is a predictive marker of anthracycline-based neoadjuvant chemotherapy efficacy. Breast Cancer Res Treat 135: 531-537, 2012.

32. Parker AS, Eckel-Passow JE, Serie D, Hilton T, Parasramka M, Joseph RW, Wu KJ, Cheville JC and Leibovich BC: Higher expression of topoisomerase II alpha is an independent marker of increased risk of cancer-specific death in patients with clear cell renal cell carcinoma. Eur Urol 66: 929-935, 2014.

33. Barr FA, Silljé HH and Nigg EA: Polo-like kinases and the orchestration of cell division. Nat Rev Mol Cell Biol 5: 429-440, 2004.

34. Kufer TA, Silljé HH, Körner R, Gruss OJ, Meraldi P and Nigg EA: Human TPX2 is required for targeting Aurora-A kinase to the spindle. J Cell Biol 158: 617-623, 2002.

35. Parvin JD, Kais Z, Arora M, Kotian S, Zha A, Ransburgh D, Bozdag D, Catalyurek $U$ and Huang K: Identification of a breast cancer associated regulatory network. In: Proceedings of the 2009 Ohio Collaborative Conference on Bioinformatics. Bioinformatics, Cleveland, OH, pp71-75, 2009.

36. Taylor SS, Scott MI and Holland AJ: The spindle checkpoint: A quality control mechanism which ensures accurate chromosome segregation. Chromosome Res 12: 599-616, 2004. 
37. Kolodner RD and Marsischky GT: Eukaryotic DNA mismatch repair. Curr Opin Genet Dev 9: 89-96, 1999.

38. Rath $\mathrm{O}$ and Kozielski F: Kinesins and cancer. Nat Rev Cancer 12 $527-539,2012$

39. Yu Y and Feng YM: The role of kinesin family proteins in tumorigenesis and progression: Potential biomarkers and molecular targets for cancer therapy. Cancer 116: 5150-5160, 2010.

40. Hong KU, Kim E, Bae CD and Park J: TMAP/CKAP2 is essential for proper chromosome segregation. Cell Cycle 8: 314-324, 2009.
41. DeLuca JG, Dong Y, Hergert P, Strauss J, Hickey JM, Salmon ED and McEwen BF: Hec1 and nuf2 are core components of the kinetochore outer plate essential for organizing microtubule attachment sites. Mol Biol Cell 16: 519-531, 2005.

(†) $\odot$ This work is licensed under a Creative Commons cc) Attribution-NonCommercial-NoDerivatives 4.0 International (CC BY-NC-ND 4.0) License. 